Lin, Q.X., and I.A. Mendelssohn. 1998. The combined effects of phytoremediation and biostimulation in enhancing habitat restoration and oil degradation of petroleum contaminated wetlands. Ecol. Eng. 10:263-274.

Loehr, R.C., and M.T. Webster. 1996. Behavior of fresh vs aged chemicals in soil. J. Soil Contam. 5:361-383.

McCutcheon, S.C. 1998. Phytoremediation: Applications and limitations. PBI Bulletin, Sept. 1998. National Res. Council for Canada, Saskatoon, SK, Canada.

Pepper, I., C. Gerba, and J. Brendecke. 1995. Environmental microbiology. Academic Press, New York.

Qui, X., S.I. Shah, E.W. Kendall, D.L. Sorenson, R.C. Sims, and M.C. Engelke. 1994. Grass-enhanced bioremediation for clay soils contaminated with polynuclear aromatic hydrocarbons. p. 142-157. In Bioremediation through rhizosphere technology. Am. Chem. Soc., Washington, DC

Rasiah, V., R.P. Voroney, and R.G. Kachanoski. 1992. Biodegradation of an oily waste as influenced by nitrogen forms and sources. Water Air Soil Pollut. 65:143-151.

Raven, P.H., R.F. Evert, and S.E. Eichhorn. 1986. Biology of plants. 4th ed. Worth Publ., New York.

Schwab, A.P., and M.K. Banks. 1994. Biologically mediated dissipa- tion of polyaromatic hydrocarbons in the root zone. p. 132-141. In Bioremediation through rhizosphere technology. Am. Chem. Soc., Washington, DC.

Schwab, A.P., J. Su, S. Wetzel, S. Pekerak, and M.K. Banks. 1999 Extraction of petroleum hydrocarbons from soil by mechanical shaking. Environ. Sci. Technol. 33:1940-1945.

Simmons, K., P. Kostecki, and E. Calabrese. 1999. State by state groundwater cleanup standards. Soil and Groundwater Cleanup. April/May. p. 10-21.

Soil Conservation Service. 1993. Part 623 national engineering handbook. Chapter 2. Irrigation water requirements. USDA, Washington, DC.

Tate, R.L. 1997. Soil microbiology. John Wiley \& Sons, New York.

Watkins, J.W., D.L. Sorenson, and R.C. Sims. 1994. Volatilization and mineralization of naphthalene in soil-grass microcosms. p. 123-131. In Bioremediation through rhizosphere technology. Am. Chem. Soc., Washington, DC.

Wollum II, A.G. 1982. Cultural methods for soil microorganisms. p. 781-802. In A.L. Page et al. (ed.) Methods of soil analysis. Part 2. Chemical and microbiological properties. 2nd ed. Agron. Monogr. 9. ASA and SSSA, Madison, WI.

\title{
Solid-State Nitrogen-15 Nuclear Magnetic Resonance Analysis of Biologically Reduced 2,4,6-Trinitrotoluene in a Soil Slurry Remediation
}

\author{
Heike Knicker,* Christof Achtnich, and Hiltrud Lenke
}

\begin{abstract}
Soil contaminated with 2,4,6-trinitrotoluene (TNT) and spiked with $\left[{ }^{14} \mathrm{C}\right]$ - and $\left[{ }^{15} \mathbf{N}_{3}\right]$-TNT was subjected to an anaerobic-aerobic soil slurry treatment and subsequently analyzed by radiocounting and solid-state ${ }^{15} \mathbf{N}$ nuclear magnetic resonance (NMR) spectroscopy. This treatment led to a complete disappearance of extractable radioactivity originating from TNT and almost all of the radioactivity was recovered in the insoluble soil fraction. As revealed by solid-state ${ }^{15} \mathrm{~N}$ NMR, a major fraction of partially reduced metabolites of TNT was immobilized into the soil during the early stage of the anaerobic treatment, although some of the compounds (i.e., aminodinitrotoluenes and azoxy compounds) were extractable by methanol. Considerable ${ }^{15} \mathbf{N}$ intensity was assigned to condensation products of TNT metabolites. A smaller signal indicated the formation of azoxy $\mathbf{N}$. This signal and the signal for nitro groups were not observed at the end of the anaerobic phase, revealing further reduction and/or transformation of their corresponding compounds. An increase of the relative proportion of the condensation products occurred with increasing anaerobic incubation. Aerobic incubation resulted in a further decrease of aromatic amines, presumably due to oxidative transformations or their involvement in further condensation reactions. The results of the study demonstrate that the anaerobic-aerobic soil slurry treatment represents an efficient strategy for immobilizing reduced TNT in soils.
\end{abstract}

$\mathrm{T}$ NT REPRESENTS a common explosive in conventional weaponry. As a result of improper handling during previous manufacture, TNT and related compounds were often introduced into the environment

H. Knicker, Lehrstuhl für Bodenkunde, Technische Universität München, 85350 Freising-Weihenstephan, Germany. C. Achtnich and H. Lenke, Fraunhofer-Institut für Grenzflächen-und Bioverfahrenstechnik, 70569 Stuttgart, Germany. Received 14 Feb. 2000. *Corresponding author (knicker@pollux.weihenstephan.de).

Published in J. Environ. Qual. 30:403-410 (2001). around former ammunition plants. Thus, there is an urgent need for the cleanup of such contaminated sites. For several years, biological treatment processes have been intensively investigated for remediating TNT-contaminated soil. The processes differ in the duration and intensity of the aerobic or anaerobic incubation, amount and type of external carbon sources added, and degree of water saturation. It is well established that TNT or its metabolites are partially associated to soil organic matter when TNT-contaminated soil is treated in compost systems (Caton et al., 1994; Isbister et al., 1984; Kaplan and Kaplan, 1982; Pennington et al., 1994). In order to achieve a more complete incorporation of metabolized TNT in soil, a combined anaerobic-aerobic composting was recently proposed (Bruns-Nagel et al., 1998). Several reports deal with anaerobic or anaerobicaerobic incubations of TNT-contaminated soil in slurry systems (Boopathy et al., 1998; Funk et al., 1993, 1995; Lenke et al., 1998; Roberts et al., 1996; Shen et al., 1998; Widrig et al., 1997). A few reports postulated degradation (Funk et al., 1993, 1995; Roberts et al., 1996) or observed partial mineralization of TNT shown by ${ }^{14} \mathrm{CO}_{2}$ production (Boopathy et al., 1998; Widrig et al., 1997). Lenke et al. (1998) developed a soil slurry process for the cleanup of TNT-contaminated soil that is based on a complete immobilization of the contaminants. Anaerobic treatment followed by an aerobic phase results in irreversible binding of TNT via cometabolic reduction of the nitro groups, achieved by feeding an auxiliary substrate (i.e., glucose) during the anaerobic phase. The aerobic stage of the process leads

Abbreviations: HF, hydrofluoric acid; NMR, nuclear magnetic resonance; TNT, 2,4,6-trinitrotoluene. 
to mineralization of the fermentation products of the auxiliary substrate and presumably to a further humification of the immobilized metabolites of TNT. Recent studies with $\left[{ }^{14} \mathrm{C}\right]-\mathrm{TNT}$ revealed that a complete immobilization of the TNT reduction products can be achieved by this treatment (Achtnich et al., 1999b). At the end of the treatment, $>98 \%$ of the initial radioactivity was bound to the soil and no mineralization of TNT was observed during the entire treatment process. Similar observations were made by Shen et al. (1998). However, in order to evaluate the possibility of immobilization and incorporation of TNT metabolites into the soil organic matter as a remediation strategy, and to elucidate possible hazards of the immobilized compounds to the environment and human health, it is necessary to obtain a better understanding of the nature of the reduced TNT metabolites in soil. Metabolites of TNT must be irreversibly bound to the soil organic matter to demonstrate a safe remediation product.

Principally, there are several approaches for the investigation of the chemical structure of insoluble nitrogen in soil systems. The first involves thermolytic or chemolytic degradation of the macromolecule into small fragments that are analyzed by gas chromatography or gas chromatography-mass spectrometry. It is assumed that the fragments are representative of the original larger molecules. Because secondary reactions (rearrangement, cracking, hydrogenation, and polymerization) cannot be excluded, it is obvious that conclusions regarding the original structure of nitrogen in the macromolecular phase have to be drawn with caution. Haider et al. $(1992,1993)$ developed a more gentle derivatization technique (silylation) to analyze soil bound residues. The silylation procedure can be used to release soil organic matter and thus allows subsequent liquidphase NMR spectroscopy. The method was successfully used to demonstrate covalent binding of biologically reduced metabolites of ${ }^{15} \mathrm{~N}$-TNT to different soil fractions (Achtnich et al., 1999a).

Alternatively, solid-state ${ }^{15} \mathrm{~N}$ NMR spectroscopy represents a technique that allows the analysis of the bulk sample without major pretreatment. Previous studies, applying solid-state ${ }^{15} \mathrm{~N}$ NMR for the analysis of humic acid isolated from a soil treated by composting after $\left[{ }^{15} \mathrm{~N}\right]$-TNT addition (Knicker et al., 1999), demonstrated the potential of this technique for examining the chemical transformation of nonextractable TNT metabolites in soil systems. The advantages of this technique are that (i) insoluble fractions can also be analyzed and (ii) due to the low natural abundance of ${ }^{15} \mathrm{~N}$ in natural soils, the spectra obtained from $\left[{ }^{15} \mathrm{~N}\right]-\mathrm{TNT}$ spiked soils show only signals of the ${ }^{15} \mathrm{~N}$-labeled TNT and its transformation products. The latter, thus, allows a clear distinction of natural nitrogen compounds in soil from those of TNT metabolization.

Based on these preliminary results, the goal of the present study was to follow the chemical alterations of $\left[{ }^{15} \mathrm{~N}\right]-\mathrm{TNT}$ immobilized in a soil obtained from a former ammunition plant during an anaerobic-aerobic bioremediation process in a soil slurry. The results should enable an evaluation of the efficiency and the ecological implications of an immobilization strategy in comparison with bioremediation via a mineralization process.

\section{MATERIALS AND METHODS}

\section{Soil Slurry Experiment}

The soil used in the present study was obtained from a former TNT production site at Hessisch Lichtenau-Hirschhagen near Kassel (Germany). The soil, contaminated with approximately $350 \mathrm{mg}$ TNT $\mathrm{kg}^{-1}$ dry soil, had the following characteristics: $\mathrm{pH}$ of 7.7, organic matter of $21 \mathrm{mg} \mathrm{C}_{\text {org }} \mathrm{g}^{-1}$ dry substance, and a silt and clay content of $47 \%$ (Lenke et al., 1998). Before use, the soil was air-dried and sieved at a mesh width of $2 \mathrm{~mm}$.

The soil $(600 \mathrm{~g})$ was spiked with $2.4 \mathrm{~g}$ of $\left[{ }^{15} \mathrm{~N}_{3}\right]-\mathrm{TNT}$ (triple labeled) and $\left[{ }^{14} \mathrm{C}\right]$-TNT $\left(5.0 \times 10^{6} \mathrm{~Bq}\right)$ and added to a reactor containing $1.2 \mathrm{~L}$ of $50 \mathrm{~m} M$ sodium-potassium phosphate buffer ( $\mathrm{pH}=7.3$ ), glucose (final concentration: $10 \mathrm{mM}$ ), and mineral salts (Daun et al., 1998). After replacing air with nitrogen, the soil slurry was inoculated with a mixed bacterial culture $(20 \mathrm{~mL})$ that is able to reduce TNT to 2,4,6-triaminotoluene (TAT; Daun et al., 1998). The soil slurry was incubated at $30^{\circ} \mathrm{C}$ and the $\mathrm{pH}$ was maintained at 7.3 . Glucose $(0.5 \mathrm{mM})$ was added daily during the anaerobic stage, which took $51 \mathrm{~d}$. At the beginning of the aerobic phase, $20 \mathrm{~mL}$ of a mixed bacterial culture, capable of mineralizing the fermentation products of glucose (Lenke et al., 1998), was added and air was pumped over the soil slurry surface. After $32 \mathrm{~d}$ of the aerobic phase, the soil slurry was removed from the reactor and air-dried. The experimental set up was recently described in more detail (Achtnich et al., 1999a).

\section{Soil Sampling and Analytical Methods}

For the radioactivity measurements, aliquots of 3 to $4 \mathrm{~mL}$ of the soil slurry were taken at certain intervals from a sample port located at the bottom of the reactor. The samples were centrifuged for $10 \mathrm{~min}$ at $4000 \mathrm{rpm}$ (approximately $2500 \times \mathrm{g}$ ) and the soil pellet of each sample was extracted twice with methanol by horizontal shaking at $30^{\circ} \mathrm{C}$ for $1 \mathrm{~h}$ each. Both methanolic extracts were combined and evaporated at $30^{\circ} \mathrm{C}$ to $2 \mathrm{~mL}$. Aliquots of the extracts $(50 \mu \mathrm{L})$ were mixed with a 10-mL scintillation cocktail (Rotiszint 2200, Roth, Karlsruhe, Germany) and their ${ }^{14} \mathrm{C}$-radioactivity was determined with a $\beta$-scintillation counter (1414 Winspectral, Wallac, Turku, Finland). The ${ }^{14} \mathrm{C}$-bound radioactivity of the soil samples and the extraction residues were determined after combustion of three subsamples of $300 \mathrm{mg}$ and subsequent measurement of the evolved ${ }^{14} \mathrm{CO}_{2}$ with an oxidizer (Biological Oxidizer OX 500, Harvey Instruments, Buffalo, NY).

The dried and homogenized bulk soils before (Sample P0) and after addition of [ $\left.{ }^{15} \mathrm{~N}\right]-\mathrm{TNT}$ (P1) were subjected to solidstate ${ }^{15} \mathrm{~N}$ NMR. Further samples were obtained at the end of the anaerobic phase (P3) and aerobic phase (P4) and after $4 \mathrm{~d}$ of anaerobic incubation (P2a) from a sample port located at the bottom of the reactor. Previous studies have shown that the highest accumulation of the isomeric aminodinitrotoluenes occurs at $4 \mathrm{~d}$ of anaerobic incubation (Achtnich et al., 1999a,b). In order to determine the amount of extractable TNT and its metabolites, the soil sample was analyzed before (2a) and after (2b) methanol extraction as described above. Concentrations of TNT, the isomeric hydroxylaminodinitrotoluenes (2HADNT/4-HADNT), 2-amino-4,6-dinitrotoluene (2-ADNT), 4-amino-2,6-dinitrotoluene (4-ADNT), 2,4-diamino-6-nitro- 
toluene (2,4-DANT), 2,6-diamino-4-nitrotoluene (2,6-DANT), $2,2^{\prime}, 6,6^{\prime}$-tetranitro-4,4'-azoxytoluene (2,2' -azoxy), 4,4',6,6'tetranitro-2,2' -azoxytoluene (4,4' -azoxy), and 2,4,6-triaminotoluene (TAT) in the methanolic soil extracts were determined by reverse-phase high performance liquid chromatography (HPLC) as described by Daun et al. (1998) and Achtnich et al. (1999a).

Prior to solid-state ${ }^{15} \mathrm{~N}$ NMR spectroscopy, Sample P2a, its residue after extraction with methanol $(\mathrm{P} 2 \mathrm{~b}), \mathrm{P} 3$, and $\mathrm{P} 4$ were treated with $10 \%(\mathrm{v} / \mathrm{v})$ hydrofluoric acid (HF) in order to increase the relative amount of organic material by removing paramagnetics and mineral components. Previous studies have shown that this treatment does not induce major changes in chemical composition of soil organic material but leads to a considerable increase in NMR spectra quality (Schmidt et al., 1997). For this extraction, $5 \mathrm{~g}$ dried sample material was mixed with approximately $40 \mathrm{~mL}$ of $10 \%(\mathrm{v} / \mathrm{v}) \mathrm{HF}$. The mixture was shaken in closed beakers overnight and subsequently centrifuged. The supernatant was carefully removed. The extraction was repeated three times. The extraction residues were washed with distilled water and freeze-dried. To quantify the release of labeled material during $\mathrm{HF}$ extraction the $\mathrm{HF}$ extracts of Samples $2 \mathrm{a}$ and $2 \mathrm{~b}$ were analyzed for ${ }^{14} \mathrm{C}$ radioactivity.

\section{Solid-State Nitrogen-15 Nuclear Magnetic Resonance Analysis}

The spectra were obtained on a Bruker DMX 400 spectrometer (Bruker, Rheinstetten, Germany) at a frequency of 40.55 $\mathrm{MHz}$, with the common cross polarization magic angle spinning (CPMAS) technique (Schaefer and Stejskal, 1976). A commercial Bruker double air bearing probe with 7-mm-o.d. rotors was used. The chemical shift scale was calibrated with neat glycine $(-347.6 \mathrm{ppm})$ and is reported relative to nitromethane $(=0 \mathrm{ppm})$. Tentative peak assignments are given in Table 1. The spectra were obtained at a spinning speed of 5.5 $\mathrm{kHz}$ after accumulation of 100000 to 1600000 single scans with a pulse delay of $150 \mathrm{~ms}$ and a contact time of $1 \mathrm{~ms}$. To improve the signal-to-noise ratio, a line-broadening of $100 \mathrm{~Hz}$ or $200 \mathrm{~Hz}$ was applied.
Table 1. Tentative assignment of chemical shift regions to ${ }^{15} \mathrm{~N}$ functional groups relative to nitromethan $(=0 \mathrm{ppm})($ Knicker et al., 1999; Witanowski et al., 1993; Thorn et al., 1996).

\begin{tabular}{|c|c|}
\hline $\begin{array}{l}\text { Chemical shift } \\
\text { region }\end{array}$ & Assignment \\
\hline \multicolumn{2}{|l|}{ ppm } \\
\hline 148 to 50 & azo compounds \\
\hline 50 to -25 & nitro groups \\
\hline-25 to -120 & $\begin{array}{l}\text { azoxy compounds, imines, phenoxazinones, } \\
\text { pyridines, quinolines }\end{array}$ \\
\hline-120 to -165 & nitriles, oxazoles \\
\hline-165 to -270 & $\begin{array}{l}\text { imidazoles, indoles, pyrroles, carbazoles, } \\
\text { quinolone, anilides, amides, enaminones }\end{array}$ \\
\hline-270 to $-\mathbf{3 1 0}$ & $\begin{array}{l}\text { aniline derivatives, phenoxazones, } \\
\text { hydrazines }\end{array}$ \\
\hline $\begin{array}{l}-310 \text { to }-350 \\
-359\end{array}$ & $\begin{array}{l}\text { aniline, phenylamines } \\
\text { ammonium }\end{array}$ \\
\hline
\end{tabular}

\section{RESULTS AND DISCUSSION}

\section{Carbon-14 Mass Balances}

As recently described, the anaerobic-aerobic treatment of soil originally contaminated with moderate amounts of TNT (350 $\left.\mathrm{mg} \mathrm{kg}^{-1}\right)$ spiked with $\left[{ }^{14} \mathrm{C}\right]-\mathrm{TNT}$ led to a complete removal of extractable TNT and its metabolites. After the end of the anaerobic treatment, $>98 \%$ of the radioactivity was immobilized in the soil (Achtnich et al., 1999b). To analyze the nature of the binding of TNT and its metabolites during and at the end of the treatment, a corresponding experiment was carried out with TNT-contaminated soil spiked with $\left[{ }^{14} \mathrm{C}\right]-\mathrm{TNT}$ and a higher amount of $\left[{ }^{15} \mathrm{~N}\right]-\mathrm{TNT}(4000 \mathrm{mg}$ $\mathrm{kg}^{-1}$ ). As shown in Fig. 1, the total amount of extractable radioactivity measured in the supernatant of the soil slurry and in methanolic soil extracts completely disappeared and all radioactivity was found in the soil after the end of the anaerobic-aerobic treatment $(>98 \%)$. In comparison with the experiment with moderate TNT amounts (Achtnich et al., 1999b), the immobilization process was definitely slower. Whereas in the latter experi-

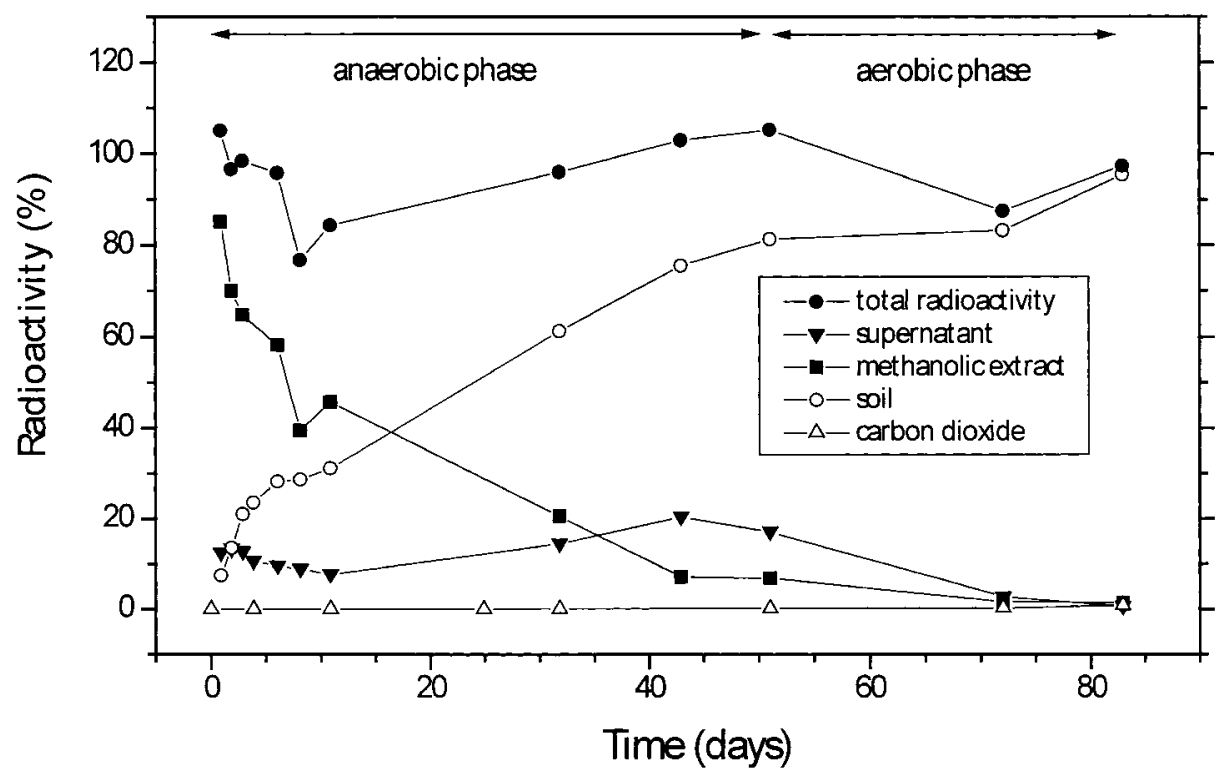

Fig. 1. Time course of the $\left[{ }^{14} \mathrm{C}\right]$ radioactivity during the biological anaerobic-aerobic treatment. The total radioactivity was calculated by the sum of radioactivity of all fractions. 


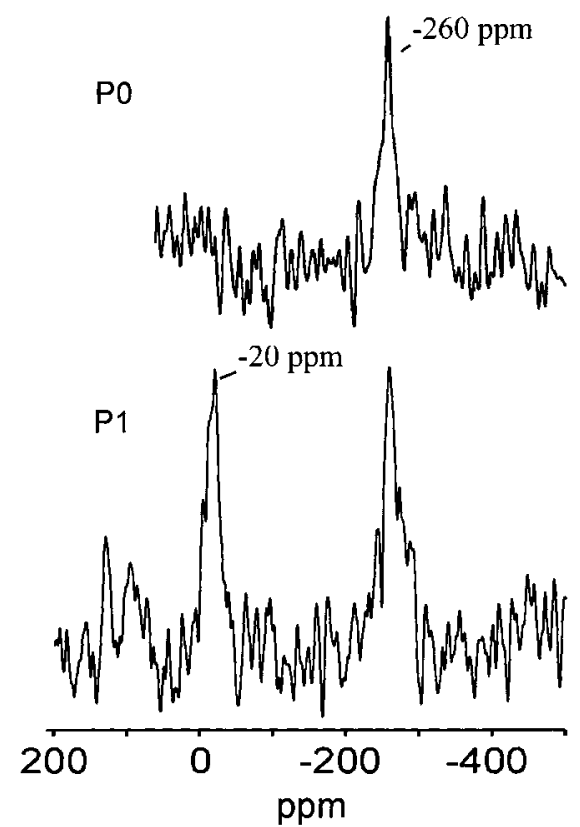

Fig. 2. Solid-state ${ }^{15} \mathrm{~N}$ nuclear magnetic resonance (NMR) spectra of a TNT-contaminated soil before (P0) and after (P1) addition of $\left[{ }^{15} \mathbf{N}\right]-\mathbf{T N T}$.

ment the majority of the radioactivity (approximately $90 \%$ ) was bound after $20 \mathrm{~d}$ of the anaerobic treatment (Achtnich et al., 1999b), corresponding amounts were only shown to be immobilized during the aerobic treatment in the experiment with high amounts of TNT (52-83 d, Fig. 1). This indicates that a longer incubation period is necessary for sufficient immobilization when higher concentrations of TNT are found in soil.

No mineralization of TNT was observed during the entire anaerobic-aerobic treatment process. Similarly, minute mineralization rates of TNT $(<0.3 \%)$ were measured in microcosms simulating bioslurry reactors with $40 \%$ soil content under anaerobic conditions (Shen et al., 1998). Sequential aerobic treatment did not improve the mineralization rate of TNT. In contrast to these soil slurry studies performed under anaerobic (Shen et al., 1998) or combined anaerobic-aerobic conditions (Achtnich et al., 1999a,b), a laboratory study of a soil slurry bioremediation process indicated that $20 \%$ of the added $\left[{ }^{14} \mathrm{C}\right]-\mathrm{TNT}$ was transformed to ${ }^{14} \mathrm{CO}_{2}$ (Widrig et al., 1997). A part of the $\left[{ }^{14} \mathrm{C}\right]-\mathrm{TNT}$ was also bound to the soil fraction or in the biomass, indicating that immobilization of metabolized TNT cannot be avoided even if a part of TNT is mineralized.

\section{Solid-State Nitrogen-15 Nuclear Magnetic Resonance Spectra of the Untreated Soil}

The solid-state ${ }^{15} \mathrm{~N}$ NMR spectrum of the TNT-contaminated soil before addition of $\left[{ }^{15} \mathrm{~N}_{3}\right]$-TNT (P0, Fig. 2) shows a comparable feature to solid-state ${ }^{15} \mathrm{~N}$ NMR spectra obtained from naturally formed soils (Knicker et al., 1993) and biological soil organic matter precursors (Knicker et al., 1997). Its intense signal at $-260 \mathrm{ppm}$ reflects that most of the organic nitrogen is associated with amide $\mathrm{N}$, most probably originating from biologi- cally humified soil organic material. Signals of the nitro groups of TNT and its metabolites, expected between 0 and $-30 \mathrm{ppm}$, cannot be distinguished from the background noise, revealing that such compounds do not comprise a considerable fraction of the organic nitrogen in this soil. Similar observations were made in extracts of the soil using liquid-state ${ }^{15} \mathrm{~N}$ NMR spectroscopy (Achtnich et al., 1999a). On the other hand, compounds such as anilides, quinolines, enaminones, quinones, indoles, or pyrroles (Witanowski et al., 1993), are also expected to give resonance lines in the chemical shift region between -170 to $-270 \mathrm{ppm}$ (Table 1 ). Signals of these compounds may be masked by the broadness of the main signal at $-260 \mathrm{ppm}$.

Addition of $\left[{ }^{15} \mathrm{~N}_{3}\right]$-TNT to the contaminated soil prior to incubation resulted in a additional signal around -20 ppm in the solid-state ${ }^{15} \mathrm{~N}$ NMR spectrum (Fig. 2, P1). However, the relative intensity for the amide signal at $-260 \mathrm{ppm}$ visually accounts for approximately the same amount as observed for the peak around $-20 \mathrm{ppm}$. Considering the high amount of added $\left[{ }^{15} \mathrm{~N}_{3}\right]$-TNT, it is obvious that the relative contribution of nitro groups from the $\left[{ }^{15} \mathrm{~N}_{3}\right]$-TNT to the total nitrogen of the sample is underestimated by the solid-state ${ }^{15} \mathrm{~N}$ NMR spectrum. This may be related to intensity losses caused by saturation effects occurring if the proton spin system was not allowed to completely relax between the single scans due to insufficiently long pulse delays. For humified material of biogenic precursors and humified TNT metabolites, pulse delays of $150 \mathrm{~ms}$ were found to be sufficiently long to avoid saturation (Knicker and Lüdemann, 1995; Knicker et al., 1999). However, for pure $\left[{ }^{15} \mathrm{~N}_{3}\right.$ ]-TNT, a proton-spin-relaxation time of $16 \mathrm{~s}$ was previously determined (Knicker et al., 1999). Generally, the pulse delay between single scans should be five times the proton spin-lattice relaxation time to obtain solidstate cross polarization magic angle spinning (CPMAS) NMR spectra that are quantitative. Consequently, to avoid saturation effects in the NMR spectrum discussed here, a pulse delay of at least $80 \mathrm{~s}$ must be applied. Considering that the accumulation of several thousands to millions of scans is necessary to obtain solid-state ${ }^{15} \mathrm{~N}$ NMR spectra of soils with acceptable signal-to-noise ratio in order to quantify free TNT in soil, a solidstate ${ }^{15} \mathrm{~N}$ NMR spectrum could only be obtained after infeasibly long measurement times. Thus, when applying the acquisition parameter that has shown to result in quantifiable solid-state ${ }^{15} \mathrm{~N}$ NMR spectra of humified TNT components (Knicker et al., 1999), one has to keep in mind that the relative contribution of free $\left[{ }^{15} \mathrm{~N}_{3}\right]$-TNT and its mobile metabolites will be underestimated.

\section{Solid-State Nitrogen-15 Nuclear Magnetic Resonance Spectra of the Treated Soil during the Early Anaerobic Phase}

The solid-state ${ }^{15} \mathrm{~N}$ NMR spectrum of the $\left[{ }^{15} \mathrm{~N}_{3}\right]$-TNT spiked soil after the anaerobic incubation period of $4 \mathrm{~d}$ (P2a, Fig. 3) shows a strong signal at $-10 \mathrm{ppm}$ in the region of the nitro groups. This indicates an incomplete 

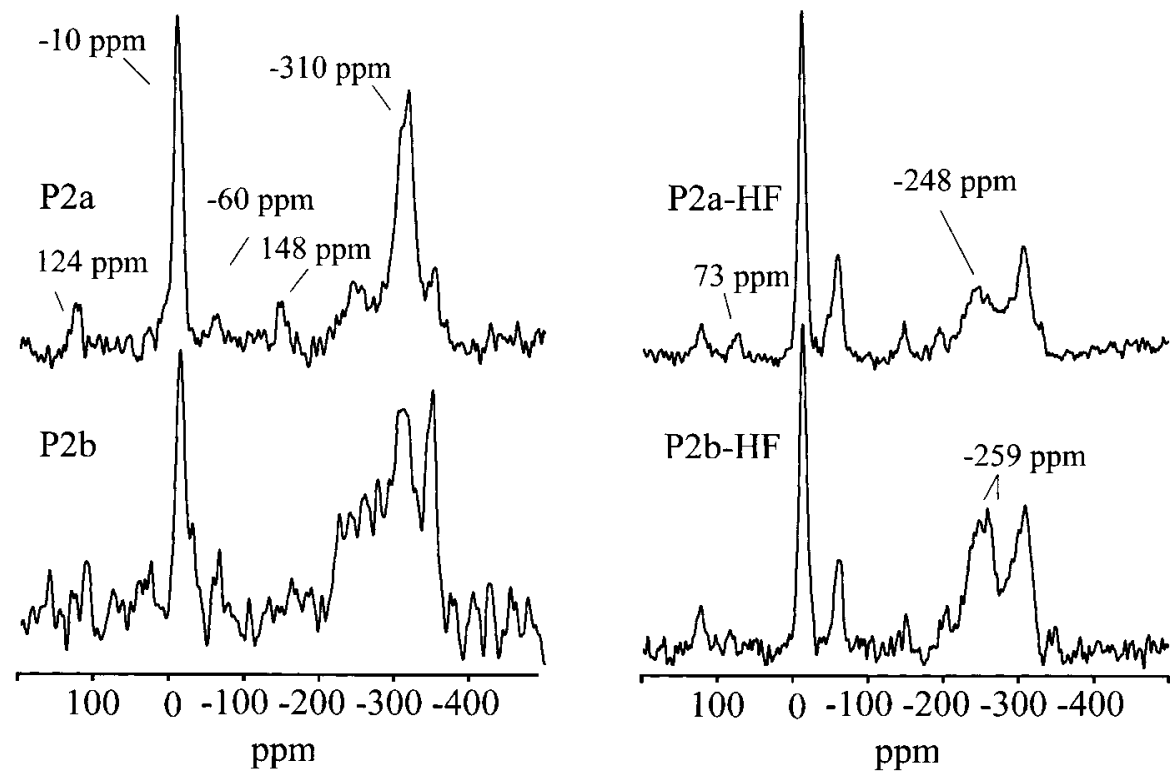

Fig. 3. Solid-state ${ }^{15} \mathrm{~N}$ nuclear magnetic resonance (NMR) spectra of a $\left[{ }^{15} \mathrm{~N}\right]-$ and $\left[{ }^{14} \mathrm{C}\right]-\mathrm{TNT}$ spiked soil incubated for $4 \mathrm{~d}$ under anaerobic conditions. Sample P2a represents the bulk sample, P2b its residue after methanol extraction. Samples P2a-HF and P2b-HF are the residues of P2a and P2b after extraction with $10 \%$ hydrofluoric acid.

reduction of all nitro groups in $\left[{ }^{15} \mathrm{~N}_{3}\right]-\mathrm{TNT}$ and/or its metabolites. Note that, relative to the spectra of $\mathrm{P} 0$ and P1 (Fig. 2), a downfield shift of the nitro signal occurred, which may indicate a change in the chemical environment of the nitro groups. The smaller signals at 124 and $-148 \mathrm{ppm}$ are assigned to spinning side bands of the peak at $-10 \mathrm{ppm}$ due to the incomplete removal of the chemical shift anisotropy by insufficiently high rotation of the sample around the magic angle.

The small signal at $-60 \mathrm{ppm}$ appears in the chemical shift range of imines, pyridinic $\mathrm{N}$, or azoxy compounds. A considerable amount of $2,2^{\prime}$-azoxy and $4,4^{\prime}$-azoxy was measured in the methanol extract of the soil sample (Table 2). It was suggested that these compounds were formed from the isomeric hydroxylaminodinitrotoluenes that exhibit their highest concentration (400 mg $\mathrm{kg}^{-1}$ dry soil) after $1 \mathrm{~d}$ of the anaerobic incubation (Achtnich et al., 1999a). Based on these observations, it can be concluded that most of the signal intensity of the peak at $-60 \mathrm{ppm}$ originates from such azoxy compounds.

Beside these signals, a strong and broad resonance line is observed in the region of aromatic amines between -270 and $-340 \mathrm{ppm}$, demonstrating that a considerable number of nitro groups were reduced to amino groups during the anaerobic incubation. The main intensity occurs in the lowfield range of the region and indicates the presence of deshielding groups (Witanowski et al., 1993) present in aminonitrotoluenes. The assignment of this signal to such compounds is supported by the results shown in Table 2, indicating that high amounts of reduced TNT metabolites, such as 2-ADNT and 4-ADNT, were still free and desorbable with methanol during the early stage of the anaerobic treatment.

The shoulder on the lowfield side of the resonance signal at $-310 \mathrm{ppm}$ in the chemical shift region between -200 and $-270 \mathrm{ppm}$ may originate from pyrroles, in- doles, quinolones, or quinolines but also from anilides, enaminones, and anilinquinones. Although the low resolution of this shoulder does not allow a more detailed assignment of this signal to specific functional groups and thus a detailed description of a metabolic pathway, the high intensity in this chemical shift region clearly demonstrates that condensation reactions of reduced $\left[{ }^{15} \mathrm{~N}_{3}\right]$-TNT metabolites occurred.

To determine if the compounds identified in the solidstate ${ }^{15} \mathrm{~N}$ NMR spectrum are incorporated into the native soil organic material, the residue after methanol extraction (Fig. 3, P2b) was subjected to solid-state ${ }^{15} \mathrm{~N}$ NMR spectroscopy. Approximately $75 \%$ of the total radioactivity of the sample was detected in the methanol extract while $24 \%$ remained in the residue after extraction (Fig. 1). This reveals that the extraction with methanol did not result in a complete removal of TNT metabolites. This observation is supported by the solid-state ${ }^{15} \mathrm{~N}$ NMR spectrum of the extraction residue showing signals at $-10 \mathrm{ppm}$ (nitro groups), $-60 \mathrm{ppm}$ (azoxy groups), and a broad resonance line embracing the region between -200 and $-340 \mathrm{ppm}$. As indicated by the

Table 2. Total amount of the soil contaminants during the biological anaerobic-aerobic treatment in a soil slurry. n.d. $=$ not detectable.

\begin{tabular}{|c|c|c|c|c|}
\hline Contaminant & After 0 d & After 4 d & After $51 \mathrm{~d} \dagger$ & After $83 \mathrm{~d}$ \\
\hline & & m & $\mathrm{g} \mathrm{kg}^{-1}$ & \\
\hline TNT & 2889.0 & 35.5 & 13.5 & 8.6 \\
\hline 2-HADNT/4-HADNT & n.d.§ & n.d. & n.d. & n.d. \\
\hline 2-ADNT/4-ADNT & 91.0 & 229.3 & 9.5 & 4.7 \\
\hline 2,4-DANT & n.d.§ & 1.94 & n.d. & n.d. \\
\hline 2,6-DANT & n.d.§ & n.d. & 1.8 & n.d. \\
\hline TAT & n.d. & n.d. & n.d. & n.d. \\
\hline $2,2^{\prime}-\operatorname{azoxy}$ & n.d. & 22.5 & n.d. & n.d. \\
\hline $4,4^{\prime}-a z o x y$ & n.d. & 335.5 & 8.6 & 6.5 \\
\hline
\end{tabular}

$\dagger$ End of the anaerobic treatment.

$\$$ End of the aerobic treatment.

$\S$ Detection limit $1 \mathbf{m g ~ k g}^{-1}$. 


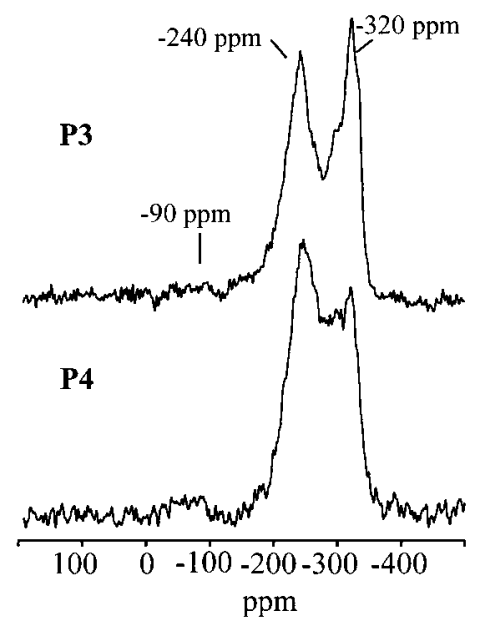

Fig. 4. Solid-state ${ }^{15} \mathrm{~N}$ nuclear magnetic resonance (NMR) spectra of hydrofluoric acid (HF)-treated $\left[{ }^{15} \mathrm{~N}\right]-$ and $\left[{ }^{14} \mathrm{C}\right]-\mathrm{TNT}$ spiked soils after $51 \mathrm{~d}$ of anaerobic incubation (P3) and after termination of the subsequent aerobic phase (total: $83 \mathrm{~d}$ of incubation) (P4).

relative decrease in signal intensities in the chemical shift regions of aromatic amines and nitro groups in the spectrum of the extraction residue relative to that of the whole sample, aminonitrotoluenes such as 2-ADNT and 4-ADNT were preferentially removed with methanol (Table 2). The simultaneous increase of the intensity between -200 and $-270 \mathrm{ppm}$ may reflect that the metabolites, not extractable with methanol, are predominantly condensation products.

A means of improving the signal-to-noise ratio of a solid-state ${ }^{15} \mathrm{~N}$ NMR spectrum of a soil sample is through the extraction of the sample with HF (Preston et al., 1989; Skjemstad et al., 1994; Schmidt et al., 1997). In order to test if this approach can also be applied to improve the spectrum quality of $\left[{ }^{15} \mathrm{~N}_{3}\right]$-TNT spiked soils, Samples P2a and P2b were extracted with $10 \% \mathrm{HF}$ and the residues were analyzed by solid-state ${ }^{15} \mathrm{~N}$ NMR spectroscopy. As demonstrated in Fig. 3 (P2a-HF, P2b-HF), a considerable improvement in the signal-to-noise ratios of the spectra was achieved with this treatment. In these spectra, signals appear at the same chemical shift as they are identified in the spectra obtained prior to $\mathrm{HF}$ treatment. However, alterations in the relative signal intensity distribution are observed. A clear decrease in signal intensity in the chemical shift region of aromatic amines is observed in the spectra of the HF-treated samples. The signal at $-60 \mathrm{ppm}$ (azoxy $\mathrm{N}$ ) becomes more pronounced in comparison with that in the spectra of the non-HF-treated samples. In the spectrum of Sample $\mathrm{P} 2 \mathrm{a}-\mathrm{HF}$, additional signals occur at 73 and -177 ppm. These signals, which can be assigned to spinning side bands of the resonance line at $-60 \mathrm{ppm}$, become distinguishable from the background noise due to the improved signal-to-noise ratio of the spectra. A possible explanation for the observed alteration after HF treatment may be the removal of free TNT metabolites, most probably aminodinitrotoluenes and diaminonitrotoluenes, with the aqueous phase during the extraction process. Correspondingly, $29.2 \%$ of the total radioactivity was found in the HF extracts of Sample P2a. In contrast, lower amounts of radioactivity $(6.5 \%$ of the total radioactivity) were measured in the HF extracts of Sample P2b, which was first extracted with methanol. This clearly indicates that most of the radioactivity extracted with HF corresponds to aminonitrotoluenes, which are also extractable by methanol.

\section{Solid-State Nitrogen-15 Nuclear Magnetic Resonance Spectra of the Soil after the Anaerobic Treatment}

At the end of the anaerobic incubation after $53 \mathrm{~d}$, almost $80 \%$ of the radioactivity remained in the soil (Fig. 1). From this result, it can be concluded that most of the $\left[{ }^{15} \mathrm{~N}_{3}\right]$-TNT metabolites were immobilized in the methanol insoluble soil fraction. The lack of a signal between 0 and $-30 \mathrm{ppm}$ in the solid-state ${ }^{15} \mathrm{~N}$ NMR spectrum of the HF-treated sample in Fig. 4 (Sample P3) demonstrates that at the end of the anaerobic phase almost all of the nitro groups of the $\left[{ }^{15} \mathrm{~N}_{3}\right]$-TNT were reduced. The disappearance of the sharp signal at -60 ppm corresponds with the lack of considerable amounts of extractable azoxy compounds at this stage of incubation (Table 2). The disappearance of these compounds demonstrated further reduction and/or transformation during the extended anaerobic incubation. However, instead of this sharp signal, a broad and weak signal can be observed between -50 and $-100 \mathrm{ppm}$. Such a signal was also reported in the solid-state ${ }^{15} \mathrm{~N}$ NMR spectrum of a humic acid extracted from $\left[{ }^{15} \mathrm{~N}_{3}\right]$-TNT spiked soil and in the liquid-state ${ }^{15} \mathrm{~N}$ NMR spectrum of a humic acid reacted with $\left[{ }^{15} \mathrm{~N}\right]$-aniline, and may be assignable to imine or pyridinic structures (Knicker et al., 1999; Thorn et al., 1996). Achtnich et al. (1999a), who analyzed different fractions of the same soil sample using liquid-state ${ }^{15} \mathrm{~N}$ NMR spectroscopy, found nitro groups as well as azoxy $\mathrm{N}$ in the humin fraction of the soil, which was extracted after silylation. This may indicate that the nitro and azoxy groups were not completely reduced and/or transformed, as found in the solid-state ${ }^{15} \mathrm{~N}$ NMR measurements. However, considering that with the silylation procedure an extraction of soil organic matter is still incomplete, the amount of nitro and azoxy groups may be overestimated by the liquid state ${ }^{15} \mathrm{~N}$ NMR measurements.

Almost half of the signal intensity in the spectrum of Sample P3 in Fig. 4 occurs between -170 and -270 ppm, leading to the conclusion that condensation products represent a considerable fraction of the $\left[{ }^{15} \mathrm{~N}_{3}\right]$-TNT metabolites produced during the anaerobic incubation. Note that this region also includes the chemical shift region of amides and peptides. Signals of natural soil material, but also peptide-like compounds formed due to incorporation of nitrogen from $\left[{ }^{15} \mathrm{~N}_{3}\right]$-TNT metabolites into microbial biomass, may be masked by the broad signal peaking at $-245 \mathrm{ppm}$. However, due to the low resolution of this signal, an estimation to what extent such amide functional groups contribute to the total signal intensity in this chemical shift region cannot be made.

The strong signal between -270 and -340 ppm shifts 
toward higher fields relative to the spectra shown in Fig. 2 and 3 and peaks at $-320 \mathrm{ppm}$. This is explained by the loss of more deshielding nitro groups in the aromatic amines due to further reduction during the anaerobic incubation.

\section{Solid-State Nitrogen-15 Nuclear Magnetic Resonance Spectra of the Soil after the Entire Treatment}

At the end of the aerobic phase ( $83 \mathrm{~d})$, the signal intensity of the resonance line at $-320 \mathrm{ppm}$ in the spectrum of Sample P4 decreases relative to that between -170 and -270 ppm of Sample P3 (Fig. 4). A possible explanation may be an oxidative transformation of free amino groups under aerobic conditions or the progressive condensation of those free amino groups to compounds such as phenoxazines, anilidines, indoles, pyrroles, or chinolines. As indicated by the increase of the signal between -50 and $-100 \mathrm{ppm}$ relative to that in the spectrum of Sample P3, condensation to imines or pyridines may have also occurred. A possible pathway may be the reaction of the amino groups with $\alpha, \beta$-unsaturated carbonyl compounds. It was suggested that 1,4 additions lead to the formation of nonhydrolysable $\mathrm{C}-\mathrm{N}$ bonds (Parris, 1980; Volkel et al., 1995). Alternatively, the formation of $\mathrm{C}=\mathrm{N}$ bonds through Schiff bases was proposed (Parris, 1980). Additionally, numerous radical reactions of aromatic amines were described that correspond to the proposed autooxidation reactions of phenol in natural humification processes (Bollag et al., 1983; Liu et al., 1987; Ziechmann, 1994). Additionally, recent NMR studies have indicated that aniline may also react with quinoid structures of native humic substances via 1,4 addition (Thorn et al., 1996).

\section{SUMMARY AND CONCLUSIONS}

The objective of the present study was the solid-state ${ }^{15} \mathrm{~N}$ NMR spectroscopic examination of the transformation of TNT during an anaerobic-aerobic bioremediation treatment of a $\left[{ }^{15} \mathrm{~N}_{3}\right]$-TNT spiked soil slurry. As previously reported (Achtnich et al., 1999a,b), during the first few days of the anaerobic incubation, the ${ }^{15} \mathrm{~N}$ NMR data demonstrate that a considerable amount of TNT was reduced to aminodinitrotoluene and diaminonitrotoluene. A portion of the nitrogen function of the TNT metabolites was involved in condensation reactions, as indicated by signals of azoxy $\mathrm{N}$ and signals in the chemical shift region of indoles, pyrroles, quinolines, and anilidines, enamines, or amides. Because of the low resolution of the latter, however, a more specific assignment cannot be made. Although a considerable part of the azoxy compounds such as 2,2'-azoxy and $4,4^{\prime}$ azoxy were extractable by methanol (Table 2 ), the major fraction of the initial immobilized residues was also due to azoxy species.

Under further anaerobic conditions, azoxy $\mathrm{N}$ and nitro groups were no longer detectable in the ${ }^{15} \mathrm{~N}$ NMR spectrum, indicating that they were almost completely reduced and/or transformed.

Condensed TNT metabolites and aromatic amines make up the majority of the bound residues in the soil sample at the end of the anaerobic phase. The relative decrease of aromatic amines during the aerobic phase may be caused by oxidative transformations of free amino groups and subsequent condensation reactions that seem to become incorporated into the soil organic matter.

Remobilization studies further indicated a high stability of TNT metabolites formed after the anaerobicaerobic soil slurry treatment (Achtnich et al., 1999b) and ecotoxicological tests could not demonstrate a hazardous liberation of toxic metabolites (Lenke et al., 1998). As such, incorporated TNT reduction products are therefore expected to be immobilized for a prolonged time span. Immobilization of biologically reduced TNT via anaerob-aerob bioremediation of soil slurry presents a promising bioremediation strategy for many soils contaminated by warfare industries. However, considering the significant differences in chemical structure of the nitrogen fraction of immobilized TNT metabolites and soil organic material formed under natural conditions (Knicker et al., 1993, 1997; Knicker and Lüdemann, 1995), the long-term effect of this immobilization on soil ecology should still be elucidated.

\section{ACKNOWLEDGMENTS}

The work was supported by Deutsche Bundesstiftung Umwelt, Osnabrück, Germany.

\section{REFERENCES}

Achtnich, C., E. Fernandes, J.-M. Bollag, H.-J. Knackmuss, and H. Lenke. 1999a. Covalent binding of reduced metabolites of $\left[{ }^{15} \mathrm{~N}_{3}\right]$ TNT to soil organic matter during a bioremediation process analyzed by ${ }^{15} \mathrm{~N}$ NMR spectroscopy. Environ. Sci. Technol. 33:4448-4456

Achtnich, C., U. Sieglen, H.-J. Knackmuss, and H. Lenke. 1999b. Irreversible binding of biologically reduced 2,4,6-trinitrotoluene to soil. Environ. Toxicol. Chem. 18:2416-2423.

Bollag, J.-M., R.D. Minard, and S.Y. Liu. 1983. Cross-linkage between anilines and phenolic humus constituents. Environ. Sci. Technol. 17:72-80.

Boopathy, R., J. Manning, and C.F. Kulpa. 1998. A laboratory study of the bioremediation of 2,4,6-trinitrotoluene-contaminated soil using aerobic/anoxic soil slurry reactor. Water Environ. Res. 70:80-86.

Bruns-Nagel, D., O. Drzyzga, K. Steinbach, T.C. Schmidt, E. von Löw, T. Gorontzy, K.-H. Blotevogel, and D. Gemsa. 1998. Anaerobic/ aerobic composting of 2,4,6-trinitrotoluene-contaminated soil in a reactor system. Environ. Sci. Technol. 32:1676-1679.

Caton, J.E., C. Ho, R.T. Williams, and W.H. Griest. 1994. Characterization of insoluble fractions of TNT transformed by composting. J. Environ. Sci. Health A 29:659-670.

Daun, G., H. Lenke, M. Reuss, H.-J. Knackmuss. 1998. Biological treatment of TNT-contaminated soil. I. Anaerobic cometabolic reduction and interaction of TNT and metabolites with soil components. Environ. Sci. Technol. 32:1956-1963.

Funk, S.B., D.L. Crawford, R.L. Crawford, G. Mead, and W. DavisHoover. 1995. Full-scale anaerobic bioremediation of trinitrotoluene contaminated soil. Appl. Biochem. Biotech. 51/52:625-633.

Funk, S.B., D.J. Roberts, D.L. Crawford, and R.L. Crawford. 1993 Initial-phase optimization for bioremediation of munitions compound-contaminated soils. Appl. Environ. Microbiol. 59: 2171-2177.

Haider, K., M. Spiteller, K. Reichert, and M. Fild. 1992. Derivatization of humic compounds: An analytical approach for bound organic residues. Int. J. Environ. Anal. Chem. 46:201-211.

Haider, K., M. Spiteller, A. Wais, and M. Fild. 1993. Evaluation of 
the binding mechanism of anilazine and its metabolites in soil organic matter. Int. J. Environ. Anal. Chem. 53:125-137.

Isbister, J.D., G.L. Anspach, J.F. Kitchens, and R.C. Doyle. 1984. Composting for decontamination of soils containing explosives. Microbiologica 7:47-73.

Kaplan, D.L, and A.M. Kaplan. 1982. Thermophilic biotransformation of 2,4,6-trinitrotoluene under stimulated composting conditions. Appl. Environ. Microbiol. 44:757-760.

Knicker, H., D. Bruns-Nagel, O. Drzyga, E. von Löw, and K. Steinbach. 1999. Characterization of ${ }^{15} \mathrm{~N}$-TNT residues after an anaerobic/aerobic treatment of soil/molasses mixtures by solidstate ${ }^{15} \mathrm{~N}$ NMR spectroscopy. I. Determination and optimization of relevant NMR spectroscopic parameters. Environ. Sci. Technol. 33:343-349.

Knicker, H., R. Fründ, and H.-D. Lüdemann. 1993. The chemical nature of nitrogen in soil organic matter. Naturwissenschaften 80:219-221.

Knicker, H., R. Fründ, and H.-D. Lüdemann. 1997. Characterization of the nitrogen in plant composts and native humic material by natural-abundance ${ }^{15} \mathrm{~N}$ CPMAS and solution NMR spectra. p. 272 294. In M. Nanny, R.A. Minear, and J.A. Leenheer (ed.) Nuclear magnetic resonance spectroscopy in environmental chemistry. Oxford Univ. Press, London.

Knicker, H., and H.-D. Lüdemann. 1995. N-15 and C-13 CPMAS and solution NMR studies of N-15 enriched plant material during 600 days of microbial degradation. Org. Geochem. 23:329-341.

Lenke, H., J. Warrelmann, G. Daun, K. Hund, U. Sieglen, U. Walter, and H.J. Knackmuss. 1998. Biological treatment of TNT-contaminated soil. II. Biologically induced immobilization of the contaminants and full-scale application. Environ. Sci. Technol. 32: 1964-1971.

Liu, S.Y., R.D. Minard, and J.-M. Bollag. 1987. Soil-catalyzed complexation of the pollutant 2,6-diethylanilin with syringa acid. J. Environ. Qual. 16:48-53.

Parris, G.E. 1980. Covalent binding of aromatic amines to humates. I. Reaction with carbonyl and quinones. Environ. Sci. Technol. 14:1099-1106.
Pennington, J.C., C.A. Hayes, K.F. Myers, M. Ochman, D. Gunnison, D.R. Felt, and E.F. McCormick. 1994. Fate of 2,4,6-trinitrotoluene in a simulated compost system. Chemosphere 30:429-438.

Preston, C.M., M. Schnitzer, and J.A. Ripmeester. 1989. A spectroscopic and chemical investigation on the deashing of a humin. Soil Sci. Soc. Am. J. 53:1142-1147.

Roberts, D.J., F. Ahmad, and S. Pendharkar. 1996. Optimization of an aerobic polishing stage to complete the anaerobic treatment of munitions-contaminated soil. Environ. Sci. Technol. 30:2021-2026.

Schaefer, J., and E.O. Stejskal. 1976. Carbon-13 nuclear magnetic resonance of polymers spinning at magic angle. J. Am. Chem. Soc. 98:1031-1032.

Schmidt, M.W.I., H. Knicker, and I. Kögel-Knabner. 1997. Improvement of ${ }^{13} \mathrm{C}$ and ${ }^{15} \mathrm{~N}$ CPMAS NMR spectra of bulk soils, particle size fractions and organic material by treatment with $10 \%$ hydrofluoric acid. Eur. J. Soil Sci. 48:319-328.

Shen, C.F., S.G. Giot, S. Thiboutot, G. Ampleman, and J. Hawari 1998. Fate of explosives and their metabolites in bioslurry treatment processes. Biodegradation 8:339-347.

Skjemstad, J.O., P. Clarke, J.A. Taylor, J.M. Oades, and R.H. Newman. 1994. The removal of magnetic materials from surface soils. A solid state ${ }^{13} \mathrm{C}$ CP/MAS n.m.r. study. Aust. J. Soil Sci. 32:1215-1229.

Thorn, K.A., P.J. Pettigrew, W.S. Goldberg, and E.J. Weber. 1996 Covalent binding of aniline to humic substances. II. ${ }^{15} \mathrm{~N}$ NMR studies of nucleophilic addition reactions. Environ. Sci. Technol. 30:2764-2775.

Volkel, W., A. Lienrack, and F. Andreux. 1995. Additions-reactions of herbicides and amino-carrying metabolites on methylcatechol, a precursor of humic substances. Compt. Rend. Acad. Sci. 320:103-108.

Widrig, D.L., R. Boopathy, and J.F. Manning. 1997. Bioremediation of TNT-contaminated soil: A laboratory study. Environ. Toxicol. Chem. 16:1141-1148.

Witanowski, M., L. Stefaniak, and G.A. Webb (ed.) 1993. Nitrogen NMR spectroscopy. Annu. Rep. on NMR Spectroscopy 25. Academic Press, London.

Ziechmann, W. 1994. Huminstoffe. Verlag Chemie, Weinheim, Germany. 